\title{
Elogio da leitura
}

\section{Praise of reading}

https://doi.org/10.34112/2317-0972a2019v37n76p149-153

\section{Daniela Molina ${ }^{1}$}

MANGUEL, Alberto. O Leitor como metáfora (o viajante, a torre, e a traça). Trad. José Geraldo Couto. São Paulo, SP: Edições SESC, 2017, 148p.

O LIVRO O LEITOR COMO METÁFORA, do escritor argentino Alberto Manguel, propõe ao público um exercício de reflexão sobre o ato da leitura. Lançado em 2017 pelas Edições Sesc, a obra, escrita na forma de ensaios, apresenta um panorama da leitura, e também dos próprios leitores, desde a origem da escrita, há aproximadamente 5 mil anos, até a atualidade. Segundo o autor, "para entender o mundo, ou para tentar compreendê-lo, a tradução da experiência em linguagem não basta” (MANGUEL, 2017, p. 13).

Vivendo atualmente no interior do sul da França e dono de uma biblioteca de mais de 30 mil volumes, Alberto Manguel, além de escritor, faz da leitura a sua grande devoção. Em 2017, assumiu a direção da Biblioteca Municipal da Argentina. $\mathrm{O}$ amor pelos livros e pela leitura acompanha o autor desde a adolescência. Ainda muito jovem, Manguel teve uma convivência muito próxima com o escritor, também argentino, Jorge Luís Borges, quando este, já praticamente cego, ouvia os livros lidos para ele por Manguel. Essa íntima convivência entre

1. Faculdade de Educação da Universidade de São Paulo, São Paulo, SP, Brasil. 
eles transformou a figura de Borges, e também toda a obra desse autor, no grande referencial da produção literária de Manguel.

Em seu ensaio, Manguel recorre a três metáforas para classificar as diferentes espécies de leitores: o viajante, a torre e a traça. O primeiro, o leitor viajante, seria aquele que descobre o mundo através da leitura e que embarca na fascinante jornada da compreensão do texto. $\mathrm{O}$ segundo, a torre, busca na leitura o isolamento do mundo e o último, representado pela traça, simboliza os leitores vorazes, que leem com uma avidez indiscriminada. Essa tripla dimensão do leitor é abordada no texto de Manguel a partir de dois polos complementares (positivo/negativo) que são inerentes a cada uma delas. Assim, na dimensão da leitura como viagem temos o binômio descoberta do mundo/perdição; na perspectiva da torre, o par que se estabelece é isolamento produtivo/fuga da realidade; e, por fim, a simbologia da traça confronta aquisição de conhecimento/entupimento de informações.

Utilizandouma imagem do séculoXII, Ohomem cósmico, de Hildegard von Bingen, Alberto Manguel inicia sua obra estabelecendo uma relação entre o ato da criação de um texto, a partir de uma página em branco, com o ato da criação do universo a partir do nada. "Até onde sabemos, somos a única espécie para a qual o mundo parece ser feito de histórias”, afirma o autor (MANGUEL, 2017, p. 13).

Nas sociedades literárias o livro teria adquirido o estatuto de repositório da memória por transcender os limites do tempo e do espaço. Na mesma medida em que o texto escrito pode reproduzir a experiência de se estar no mundo, o próprio mundo foi visto, pelas culturas literárias, como um livro, passível de ser lido e interpretado.

\section{O VIAJANTE}

A metáfora do leitor viajante se relaciona à descoberta do mundo por meio do ato da leitura. "O livro é um mundo através do qual podemos viajar porque o mundo é um livro que podemos ler”, diz o autor (MANGUEL, 2017, p. 46).

Nesse sentido, tanto o mundo como o próprio livro se tornam fonte de conhecimento, já que o leitor viajante, em seu itinerário, parte do passado (o começo do livro) e percorre todo o caminho proposto pela história, tornando-se como um companheiro de viagem dos personagens, para chegar a um final desconhecido. $\mathrm{O}$ leitor se envolve nessa jornada (da literatura e da própria vida) ao entrar no jogo da suspensão da descrença e experimentar temporariamente uma sensação de irrealidade da vida cotidiana e uma espécie de transcendência em relação às dimensões 
de tempo e espaço. Assim como em sua própria vida, o leitor deixa no passado as páginas lidas, entrega-se àquelas que estão em suas mãos no presente e guarda ao futuro desconhecido as que ainda virão. A leitura exige introspecção (a necessidade de viajar só); por isso, o autor alerta para a importância de se viajar de modo a retornar com o que vemos (ou, nesse caso, com o que lemos), de maneira reflexiva e consciente, tomando o cuidado para que essa viagem (leitura) possa nos fazer sentido e nos levar em direção a algo.

Em sentido religioso, o autor traça um paralelo entre o Novo e o Velho Testamento, a partir de uma iluminura do século XV. Nela, vemos o bebê Moisés colocado em um cesto representado por um livro encadernado. A cena de Moisés abandonado às margens do Mar Vermelho, em um livro, representava, segundo Manguel, a forma como a palavra de Deus se espalhou pelo mundo. Desse modo, "o Livro é o veículo que permite que a palavra de Deus viaje pelo mundo, e os leitores que o seguirem tornam-se peregrinos no sentido mais profundo e verdadeiro" (MANGUEL, 2017, p. 20).

\section{A TORRE}

Essa imagem aparece associada à ideia do leitor isolado do mundo, que busca os espaços reclusos como uma necessidade para nutrir a vida intelectual. $\mathrm{O}$ afastamento do mundo através da busca de um lugar ideal, propício para a reflexão, denota o duplo sentido do termo "torre de marfim": o lugar do isolamento produtivo e necessário para o ato intelectual, ainda que a melancolia e a preguiça apareçam como obstáculo e, ao mesmo tempo, um espaço de fuga aos deveres do mundo, um "esconderijo" para os que se esquivam de suas responsabilidades sociais.

Essa ambiguidade simbolizada pela torre é traduzida na imagem do personagem Hamlet, como exemplo do jovem intelectual que acredita no poder do conhecimento e da erudição. Admirado por alguns por suas capacidades intelectuais, Hamlet também é visto com certa desconfiança por outros, justamente por ser incapaz de agir no mundo. Intelectuais de esquerda, diante dos movimentos sociais dos séculos XIX e XX, viam o papel do intelectual exatamente como o oposto à figura de Hamlet. Segundo Manguel, o que passa a ser valorizado é o sujeito engajado, ativo e revolucionário, e não só o portador de uma erudição. Hamlet representaria exatamente o intelectual da torre de marfim, cujo excesso de pensamento dificulta a ação. O poder intelectual de Hamlet o paralisa e, na medida em que ele vai se dando 
conta disso, através das revelações do espírito de seu pai morto, o personagem percebe que precisa descer de sua torre de marfim e agir.

\section{A TRAÇA}

A terceira metáfora proposta por Manguel mostra como esse intelectual, apartado de um convívio e de uma prática social, torna-se uma traça, ao confundir o acúmulo de livros com a aquisição de conhecimento, e ao acreditar que os personagens literários eram de fato figuras do mundo real.

A figura de Dom Quixote é utilizada por Manguel como simbologia para um tipo de leitor que, por se isolar na torre de marfim e se deixar absorver pelo universo literário, acaba confundindo a realidade dos livros com o mundo no qual vive. A "loucura” de Alonso Quijano é sua crença de que os personagens da ficção são reais. Assim, o conhecimento proveniente do isolamento na torre de marfim e da busca incessante e desmedida pelos livros (na imagem do devorador) faz com que o leitor se aliene do mundo e passe ele próprio a ser devorado pelos livros que lê.

A partir do exemplo do personagem de Cervantes, Manguel resgata a figura do "louco dos livros", uma espécie de leitor alienado que não consegue relacionar a realidade ao conhecimento adquirido. $\mathrm{O}$ autor adverte que "a traça de livros, a despeito de todos os livros devorados, permanece estúpida” (MANGUEL, 2017, p. 117).

Esse leitor voraz, que se alimenta desesperadamente das palavras sem refletir sobre seu significado, acaba sendo ele próprio devorado, como Ema Bovary, personagem de Flaubert, que, por meio dos livros, aparta-se da realidade e passa a buscar na ficção a satisfação dos seus desejos pessoais.

Manguel constrói seu texto resgatando autores clássicos e imagens esquecidas ao longo do tempo. Os capítulos são curtos e as abordagens adquirem um caráter mais geral, mas, antes de parecerem superficiais, as referências utilizadas pelo autor nos instigam a querer ler os grandes clássicos. As citações, descomprometidas com as normas acadêmicas, aparecem no texto de Manguel quase como diálogos que escritores e leitores vão estabelecendo a partir da experiência da leitura, e é o próprio autor que reconhece tal espécie de liberdade poética, justificando que isso se deve menos a um descuido e mais a um "entusiasmo de amador".

A obra de Manguel nos alerta de que é preciso refletir sobre o ofício da leitura e sobre a relação que estabelecemos com os livros, enquanto indivíduos e sociedade. Em tempos inundados de distrações, o autor lembra que a leitura exige lentidão, 
dedicação, intensidade e reflexão, valores estes justamente contrários aos propostos pelos meios digitais, pautados pela velocidade, brevidade e superficialidade.

O que Manguel faz em seu texto é uma grande homenagem à leitura. Ora nos aproximando, ora nos distanciando da imagem do leitor enquanto viagem, torre e traça, o autor nos leva à percepção de que o ato da leitura é sempre incompleto e que é essa incompletude que nos impulsiona a seguir de um texto a outro, ligando diferentes tempos e espaços, construindo sentidos e compreendendo o mundo, afinal, como o próprio autor afirma: "somos criaturas leitoras, ingerimos palavras, somos feitos de palavras, sabemos que palavras são nosso meio de estar no mundo, e é através das palavras que identificamos nossa realidade e por meio de palavras somos, nós mesmos, identificados" (MANGUEL, 2017, p. 140).

\section{SOBRE A AUTORA}

Daniela Molina é graduada em História (Universidade de São Paulo), tem Mestrado em Linguagem e Educação (Universidade de São Paulo), doutoranda em Educação, Linguagem e Psicologia (Universidade de São Paulo). Tem experiência nas áreas de Educação, Memória e Narrativa com pesquisa nos seguintes temas: Memória, Narrativa, Educação, Hermenêutica, Experiência. E-mail: daniela.historia@hotmail.com.

Recebido em 10 de janeiro de 2019 e aprovado em 27 de maio de 2019. 